Brit. F. industr. Med., 1968, 25, 235.

\title{
A Field Assessment of a Prototype Meter for Measuring the Wet-Bulb Globe-Thermometer Index
}

\author{
J. D. WALTERS \\ From the Royal Naval Medical School, Alverstoke, Gosport, Hants
}

\begin{abstract}
A prototype electronic instrument for the direct measurement of the wet-bulb globe-thermometer index is described. An assessment is made of its accuracy, as compared with W.B.G.T. indices calculated from conventional thermometric data, and a comparison is made between W.B.G.T. values read from the meter and effective or corrected effective temperatures derived from separate thermometric and air velocity recording instruments in the same climates. The instrument proved to be reliable and accurate over a wide range of climates and is a useful self-contained device for use in habitability surveys and similar investigations.
\end{abstract}

The instrument to be described was developed by Light Laboratories from an original idea put forward by Dr. H. S. Wolff of the Medical Research Council's Scientific Staff and Mr. F. E. Smith of the Council's Headquarter's Staff. Over a wide range of climates it will record directly (i.e., without the use of separate instruments) the wetbulb globe-thermometer (W.B.G.T.) value on a calibrated scale. It is an electronic instrument and, therefore, for field use has several advantages over mercurial thermometers, especially in closed environments such as submarines or spacecraft where spillage of mercury is an unacceptable hazard and in aircraft where the carriage of mercury is either discouraged or prohibited.

No reference in published papers has been found relating to any integrating electronic device for measuring the W.B.G.T. index which was developed before the prototype W.B.G.T. meter to be described, although reports on somewhat similar instruments have been published. The Envirec, described by Hosey and Mendenhall (1959), was capable of continuously recording dry-bulb, wetbulb, and globe-thermometer temperatures as well as air velocity, and W.B.G.T. values could be calculated from these data. More recently, an instrument similar in concept to the W.B.G.T. meter was developed at the United States Army Medical Equipment Research and Development Laboratory and this has been used and compared with the prototype W.B.G.T. meter by Peters

Received for publication on November 27, 1967.
(1966). Another instrument with similar capabilities was described by Lupu (1965). Lupu's instrument employed a slightly different principle in that he used silicon diodes as temperature transducers instead of thermistors and, so far as is known, no field trials to compare the results obtained with his instrument and the other available meters have been carried out.

All the integrating instruments described above compute the W.B.G.T. index according to the formula recommended by Yaglou and Minard (1956) as follows:

W.B.G.T. $=0.7$ wet-bulb +0.2 globe-thermometer $+0 \cdot 1$ dry-bulb temperature.

\section{The Prototype Wet-Bulb Globe-Thermometer Index Meter}

The prototype W.B.G.T. meter is illustrated in Fig. I with the three temperature sensors in the operating position but, for ease of transport, these sensors, including the black globe, fold away into its wooden case, II $\times 9 \times 8$ in. $(27 \times 22 \times$ $20 \mathrm{~cm}$.). A supply of distilled water, for filling the wet-bulb thermometer reservoir, and spare wicks are also carried inside the case so that the unit is self-contained.

Three thermistors are used in the W.B.G.T. meter as temperature transducers. The electrical resistance of these devices varies in a predictable way with changes of temperature and they are therefore suitable for temperature measurement. They are also small but robust and their low thermal 


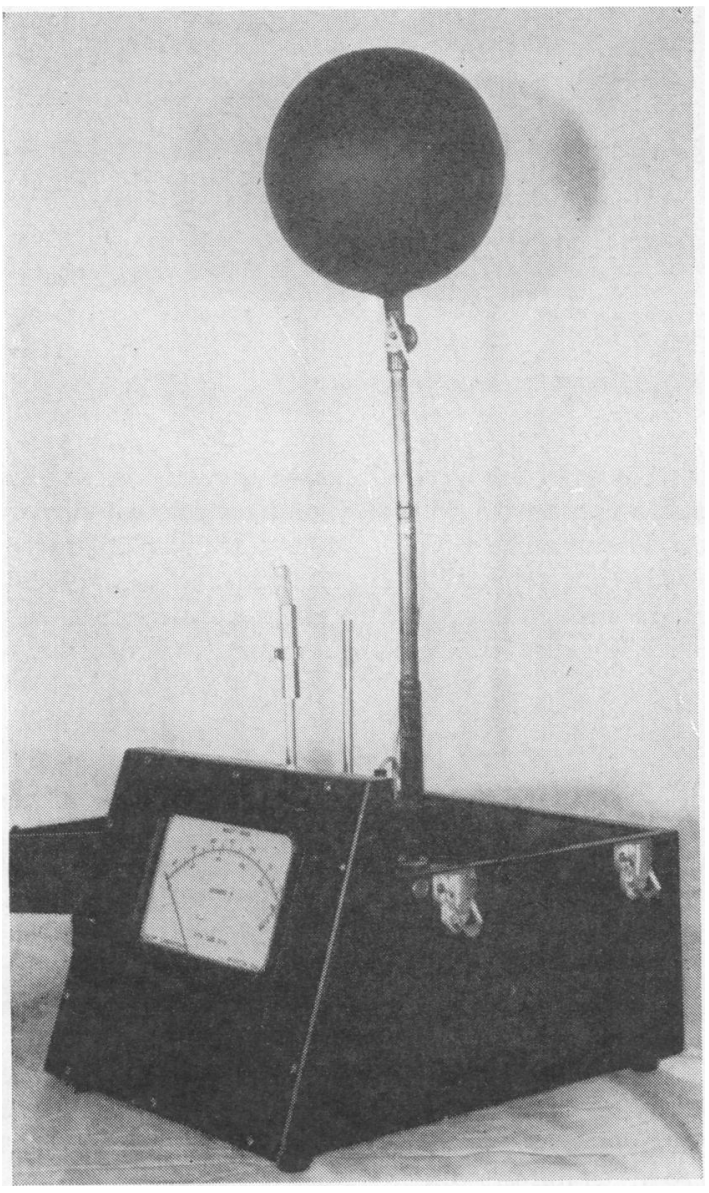

FIG. I. The prototype W.B.G.T. meter.

inertia facilitates the rapid evaluation of temperature levels.

One of the sensors is freely exposed to the environment, another is covered by a wick kept constantly moist with distilled water from a reservoir and the third is situated at the centre of a hollow black globe, 6 in. $(15 \mathrm{~cm}$.) in diameter. In the instrument described here the globe was constructed from very light gauge copper in order that the time taken for the globe temperature to stabilize could be made as short as possible. The three sensors are connected electrically so that they form one limb of a simple bridge circuit and so that each sensor contributes a proportion of the total resistance of the limb in accordance with the W.B.G.T. formula. A schematic diagram of the instrument is given in Fig. 2, from which it may be seen that the circuit also incorporates a battery voltage stabilizing device.

The W.B.G.T. meter is extremely easy to use. Having set the instrument up in the test environment as in Fig. I and waited for the globe temperature to stabilize (about 4 minutes with the special globe fitted to the prototype instrument), the selector switch is set to the 'Test' position and the reading is noted. Provided that the pointer reaches the prescribed 'battery test' mark on the display of the meter the batteries, which have a working life of at least 150 hours, are acceptable. The switch is then set to the 'On' position and the pointer reads the W.B.G.T. value directly on the scale, which in this instrument is calibrated in degrees Fahrenheit and covers a range of W.B.G.T. values from $55^{\circ} \mathrm{F}$. to $125^{\circ} \mathrm{F}$. $\left(12 \cdot 8^{\circ} \mathrm{C} .-5 \mathrm{I} \cdot 7^{\circ} \mathrm{C}\right)$. This spans a range to cover thermal environments from the lower limits of thermal comfort to conditions which are so hot as to be tolerable for a few minutes only.

A further position of the selector switch marked 'Oral' is also provided on the prototype instrument. This position is used in conjunction with a variety of probes $^{1}$ which may be plugged into a socket inside the instrument and used for the measurement of oral, rectal or any other temperature within the range $85^{\circ} \mathrm{F}$. $-110^{\circ} \mathrm{F}$. $\left(29 \cdot 4^{\circ} \mathrm{C} .-43 \cdot 3^{\circ} \mathrm{C}\right.$.). The oral temperature probe stabilizes within Io seconds. The display of the instrument is suitably calibrated and shows these temperatures in red numerals below those for the W.B.G.T. values in degrees Fahrenheit.

\section{Evaluation of the Prototype W.B.G.T. Meter}

Method No laboratory trials designed specifically to test the performance of the W.B.G.T. meter were carried out as it was thought that an assessment based on observations made in diverse practical situations would be of greater value. It was used in several of H.M. ships, in the climatic chamber at the Institute of Aviation Medicine, Farnborough, during life-raft trials, and elsewhere as and when the opportunity arose. Meter readings in each environment were compared with W.B.G.T. values derived from conventional thermometric data recorded at the same time and in the same position. In addition, air velocities were determined wherever possible in order that W.B.G.T. values and the effective or corrected effective temperatures, derived from the readings of separate instruments, in each environment could be compared. The range of climates studied was wide and the warmest was

${ }^{1}$ Available from Light Laboratories. 
FIG. 2. Schematic diagram of the prototype W.B.G.T. meter.

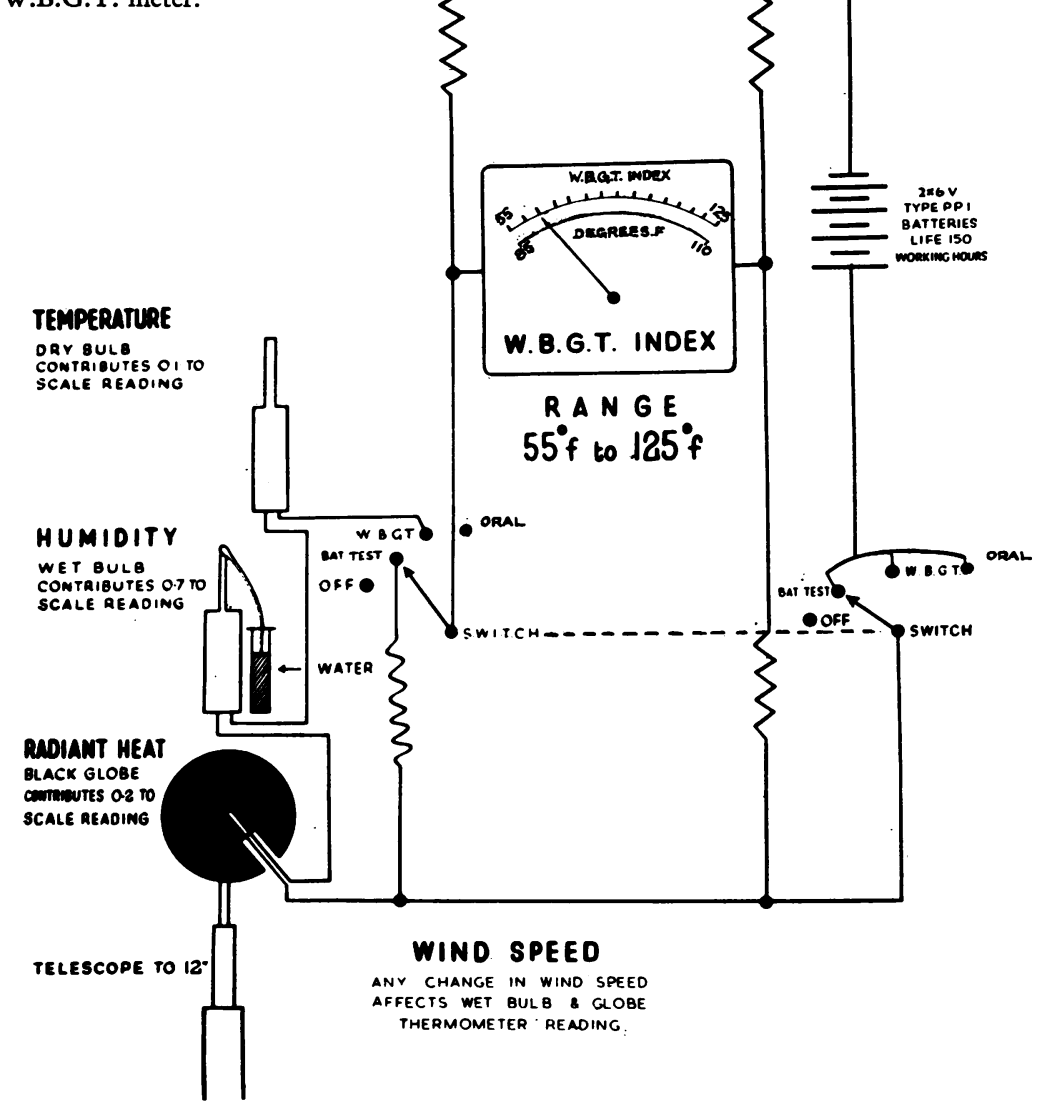

beyond the range of the nomograms for the effective or corrected effective temperatures or the predicted 4-hour sweat rate $\left(\mathrm{P}_{4} \mathrm{SR}\right)$ index (McArdle, Dunham, Holling, Ladell, Scott, Thomson, and Weiner, 1947).

Results The Table shows the climates in which the W.B.G.T. meter was evaluated, the effective or corrected effective temperatures, and the W.B.G.T. values calculated from conventional thermometric data and measured on the meter. In calculating the W.B.G.T. index the standard formula (see above) was used wherever possible but in those cases where the globe-thermometer temperature was not recorded and radiant heat was not considered to be an important factor the modified formula, W.B.G.T. value $=0.7$ wet-bulb temperature +0.3 dry-bulb temperature, was employed.

A comparison between the W.B.G.T. values calculated ( $x$ ) and measured $(y)$ is presented as a scatter diagram in Figure 3. The relationship was linear, the regression equation being $\mathrm{y}=0.969 \mathrm{x}+$ 2.64 and the correlation coefficient 0.99 . Both the regression and the correlation were highly significant $(\mathbf{P}=0.001)$. A line drawn to the regression equation is also shown in Figure 3.

The similarly close linear relationship between 
TABLE

Temperature, Air Velocity, and Three Indices of Thermal Stress derived from Conventional Thermometer OBSERVATIONS COMPARED WITH W.B.G.T. METER READINGS

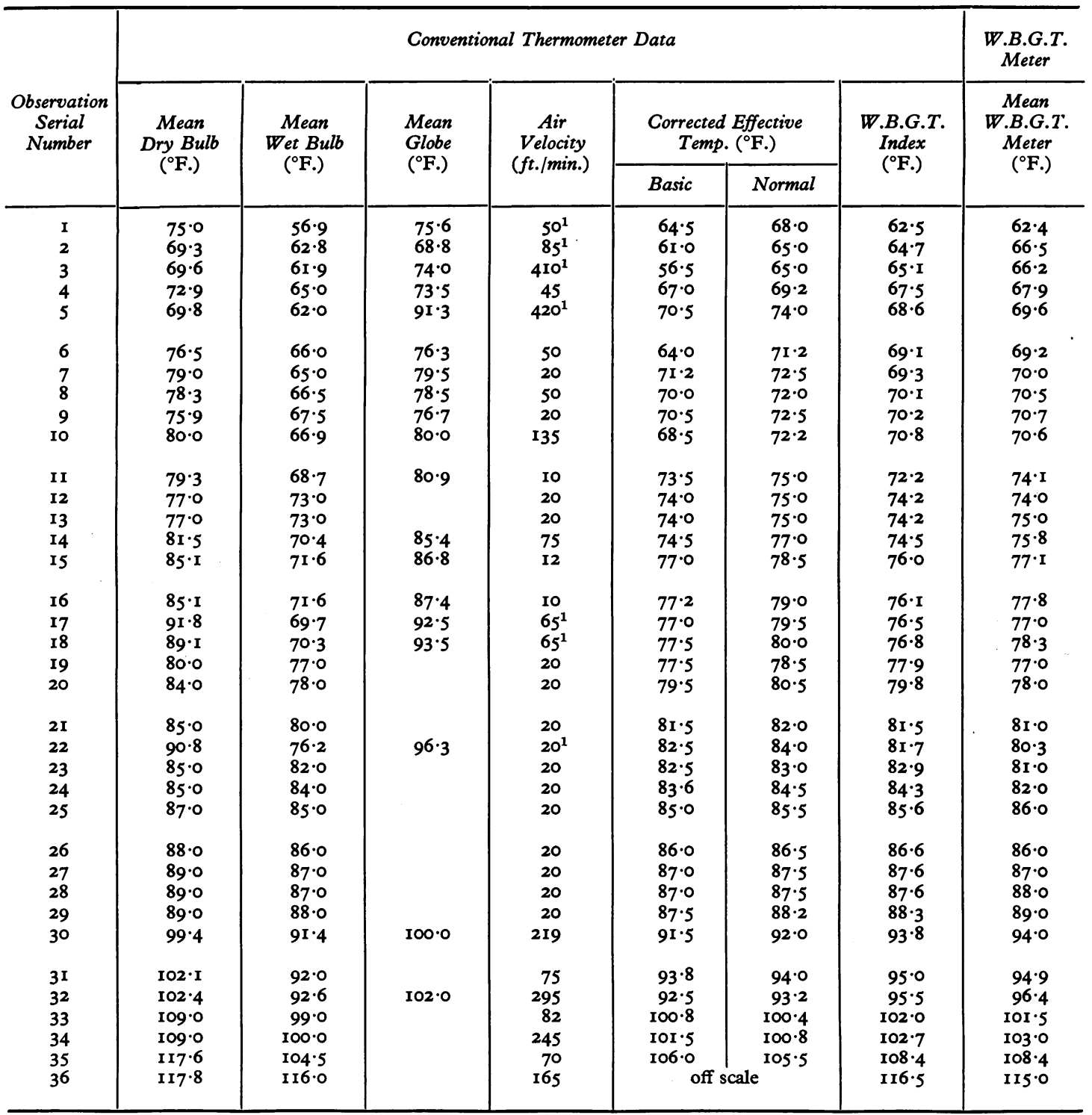

${ }^{1}$ Very variable.

normal effective or corrected effective temperatures $(x)$ and measured W.B.G.T. values (y) is illustrated in Figure 4. In constructing this diagram, reading no. 36 in the Table was omitted since the climate (II7.8 ${ }^{\circ}$ F. D.B. $/$ III $\cdot 0^{\circ}$ F. W.B., $47 \cdot 7^{\circ} \mathrm{C} . / 46 \cdot 7^{\circ} \mathrm{C}$.) was beyond the range of the effective or corrected effective temperature nomograms. Reading no. 35 in the Table was at the extremity of the nomograms and, although it has been included in Fig. 4, it has been omitted from the calculation of the regression equation and coefficient of correlation. For the remaining 34 sets of data the regression equation was 


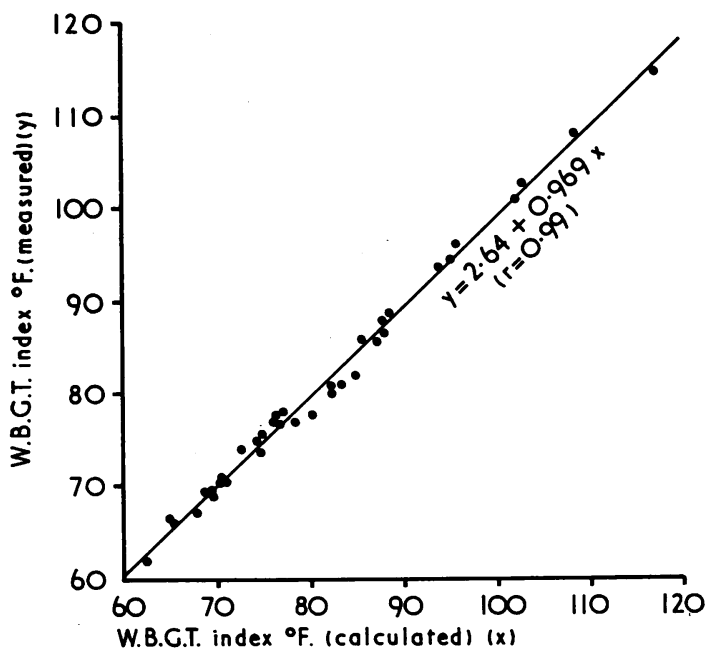

Fig. 3. Scatter diagram relating W.B.G.T. index calculated from conventional thermometric data $(x)$ and that measured by the W.B.G.T. meter (y).

$y=I \cdot I 02 x-9 \cdot 10$ and the correlation coefficient was 0.99 . Both the regression and the correlation were highly significant $(P=0.001)$. Using the same data the coefficient of correlation, between basic effective or corrected effective temperatures and measured W.B.G.T. values, was 0.98 , which does not differ significantly from that for the normal scale. The figure also approximates closely to that of $r=0.95$ reported by Davies (1963) following a comparison between basic corrected effective temperatures and W.B.G.T. values calculated from conventional thermometric data in 393 environments.

\section{Conclusions}

If the W.B.G.T. index is accepted as a suitable method for assessing climatic severity in field surveys, an instrument which measures W.B.G.T. values directly will save much time, effort, and expense. The development of highly accurate and reliable electronic temperature transducers has made the construction of such an instrument feasible, and the prototype has been shown to work well in practice.

The Royal Naval Personnel Research Committee's prototype W.B.G.T. meter is light, easily transported, robust, and easy to use and responds quickly to changes in environmental temperature. It has been shown to be accurate and produces a direct reading of W.B.G.T. values without the need for computation or nomograms, thus elimin-

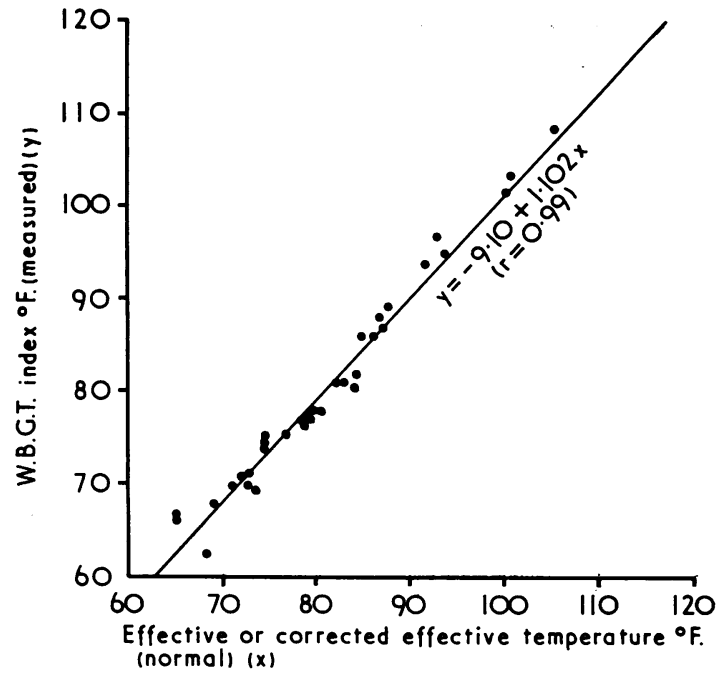

FIG. 4. Scatter diagram relating W.B.G.T. index measured by the W.B.G.T. meter and effective or corrected effective temperature.

ating one possibility of human error and greatly speeding up the initial survey of warm environments.

I am indebted to the Medical Director General (Naval), Surgeon Vice-Admiral E. D. Caldwell, C.B., Q.H.P., M.D., F.R.C.P., and the Chairman of the Royal Naval Personnel Research Committee of the Medical Research Council, Sir Lindor Brown, C.B.E., F.R.C.P., F.R.S., for permission to publish this report. In addition I am grateful to Surgeon Captain F. P. Ellis, O.B.E., R.N. for his invaluable help in the preparation of the paper, to Miss H. M. Ferres and Dr. D. McK. Kerslake for assistance in interpreting the data, to Mr. F. E. Smith, M.B.E., for much encouragement, and to Mr. A. L. Light for technical advice.

\section{REFERENCES}

Davies, W. R. (1963). Assessment of Thermal Conditions in H.M. Ships. Comparison of Corrected Effective Temperature and the Wet-bulb Globe-thermometer Index. R.N.P. 63/1036, W.V.P. 85 .

Hosey, A. D., and Mendenhall, A. C. (1959). The Envirec -an instrument for continuous recordings of environmental air, wet-bulb, and globe temperatures, and air velocity. Amer. industr. Hyg. Ass. F., 20, $121-130$.

Lupu, N. Z. (1965). A silicon dinde circuit for direct measurement of the WBGT thermal stress index. I.E.E.E. Trans. bio-med. Engng. Jan. 1965, vol. BME-12, 40-43. abstr. in I.E.E.E. Spectrum, Feb. 1965, vol. 2, 140.

McArdle, B., Dunham, W., Holling, H. E., Ladell, W. S. S., Scott, J. W., Thomson, M. L., and Weiner, J. S. (1947). The prediction of the physiological effects of warm and hot environments: The P4SR Index. Med. Res. Coun. (Lond.), R.N.P. Rep. No. 47/391. 
Peters, D. W. A. (1966). Preliminary Report on the Direct Measurement of the Wet-bulb Globe-thermometer Index. Army Personnel Research Establishment Memorandum N/2.
Yaglou, C. P., and Minard, D. (1956). Prevention of Heat Casualties at Marine Corps Training Centres. Office of Naval Research Physiology Branch, Washington, D.C. Final report under Contract No. N 50RI-07665. May, 1956.

\section{The April (I968) Issue}

The April (1968) issue contains the following papers:-

Some Electrophysiological Methods for Studying the Action of Narcotic Agents in Animals, with special reference to Industrial Solvents: A Review HANA MIKISKová, and Aloš MIKISKA

Personal Factors associated with Sickness Absence P. J. TAYLOR

Dermatitis due to the Wood Dusts of Khaya anthotheca and Machaerium scleroxylon J. W. W. MORGAN, R. J. ORSLER, and D. S. WILKINSON

Occupational Brucellosis in County Cork Bridget V. Foley, and JoHn P. Corridan

Effects of Sodium and Hydrogen Fluorides on the Metabolism of Fluorine, Calcium and Phosphorus in Rats P. Macuch, J. Kortus, G. Balazova, and J. Mayer

Withdrawal Symptoms in Workers Exposed to Nitroglycerine R. P. LUND, J. HÄGGENDAL, and G. JoHNsSON

Determination of Lead in Urine by Atomic Absorption Spectrophotometry STIG SeLANDER, and KIM CRAMÉR

A Trial of Terylene Overalls for Lead-Acid Electric Accumulator Pasters M. K. Williams, JOAN WALFORD, and E. KING

Notes and Miscellanea

Diagnostic Sodium Calciumedetate Mobilization Test in Ambulant Patients D. LAHAYE, D. ROOSELS, and R. VeRWILGHEN

Assessing the Radiological Progression of Simple Pneumoconiosis P. D. Oldham

Effect of 2,3-Dimercaptopropanol (BAL) on Urinary Excretion and Brain Content of Mercury L. Magos

Stress Fracture of the Femur: A Work Accident $\quad$ I. A. Mansoor

Book Reviews

A number of copies are still available and may be obtained from the Publishing Manager, British Medical Association, Tavistock Square, London W.C.I, price I8s. $6 \mathrm{~d}$. 